\title{
AN EFFECTIVE AND AFFORDABLE CAMERA TRAP FOR MONITORING FLOWER-VISITING BUTTERFLIES IN SANDHILLS: WITH IMPLICATIONS FOR THE FROSTED ELFIN (CALLOPHRYS IRUS)
}

\author{
Dave McElveen \& Robert T. Meyer \\ Tall Timbers Research Station, 13093 Henry Beadel Drive, Tallahassee, FL 32312. USA
}

\begin{abstract}
New advancements in camera trap technology have led to wide-spread use in animal monitoring. In this study we tested whether modern self-contained camera traps could be used to identify small lepidopterans such as the frosted elfin (Callophrys irus). A vast majority of photographed lepidopterans, 76/8I (93.83\%), were identifiable to family when moving relatively slowly across the camera's field of view. Although no $C$. irus were observed, we were able to identify several species of lepidopterans including those of similar size as C. irus. We find that modern camera traps are adequate to sample small lepidopterans and may open new avenues to survey for small rare species such as $C$. irus over larger areas than typically possible with small field crews and short flight seasons.
\end{abstract}

Keywords: Camera trap, monitoring, butterflies, sandhills, frosted elfin, Callophrys irus

\section{INTRODUCTION}

Camera traps are widely used in animal monitoring (O'Connell et al. 20I I; Kobayashi et al. 2019) and have been used successfully in monitoring butterflies and other pollinators (Steen \& Aase 20II; Edwards et al. 2015; Georgian et al. 2015; Hobbhahn et al. 2017; Phon et al. 2017; van der Kroft et al.2019). The cameras provide a useful means of monitoring butterfly activity when constraints to the use of human observers exist. Often these camera set-ups are expensive and cumbersome, thus limiting their utility. Although this technology is not new to butterfly research, the use of cameras for monitoring butterflies in Sandhill communities is relatively understudied. Sandhill environments are vital for many species including the rare frosted elfin (Callophrys irus). Recent advances in technology have led to less-expensive, self-contained "trailcam" cameras. We sought to assess how well we could detect and identify flower-visiting butterflies in a Sandhill community using the latest generation of affordable, over-the-counter trailcams.

\section{MATERIALS AND METHODS}

We conducted this study on the Apalachicola National Forest's Munson Hills Unit (MHU) south of Tallahassee, Florida. The MHU is composed of a sandhill community dominated by longleaf pine (Pinus palustris) with occasional oaks (Quercus spp.) and an understory composed of a mixture of wiregrass (Aristida stricta), bluestems (Andropogon spp.),

Received I3 August 2019, accepted 26 December 2019

*Corresponding author: d.mcelveen@comcast.net blueberries (Vaccinium spp.), huckleberries (Gaylussacia spp.) and forbs. We selected a small, discrete $\sim 2 \mathrm{~m}^{2}$ patch of sundial lupine (Lupinus perennis) with $\sim 100$ mature and immature inflorescences. L. perennis is the sole larval host plant of $C$. irus in north Florida. This patch was discovered recently and could not be included in the weekly adult surveys for $C$. irus being conducted on other $L$. perennis patches $(N$ $=\mathrm{I72})$ in the MHU. This study was timed to occur during the peak adult flight period of C. irus in 2019.

Both sexes of $C$. irus feed on mature L. perennis flowers and females preferentially oviposit on immature L. perennis inflorescences (Swengel 1996; Thom \& Daniels 2017). During oviposition, females typically slowly walk on the immature inflorescence while touching and probing with their antennae and abdomen, often spending several minutes at a time on an individual inflorescence (pers. obs.). This behavior lends itself to potential successful capture with a camera trap.

In preparation for this study, we evaluated two popular trailcam models for their ability to document $C$. irus-sized flying insects on photographs taken with each. We compared the StealthCam model STC-DS4K (\$160-I70 from discount retailers) and the Day 6 PlotWatcher Pro model TLC-200-C (\$245-260) for four important factors: field of view (FOV), exposure quality in varying light conditions, image storage capacity, and image resolution. Both models had similar FOVs and image storage capacity, but the StealthCam was much better at recording properly exposed images in both full sunlight and shade. Most importantly, the StealthCam had 16 megapixel native resolution compared to $<2$ megapixels in the PlotWatcher. This resulted in far better image resolution in the StealthCam, especially when zoomed in.

We affixed the StealthCam model on a vertical stake $\sim$ Im off the ground and $\sim \mathrm{Im}$ from the nearest edge of the target 

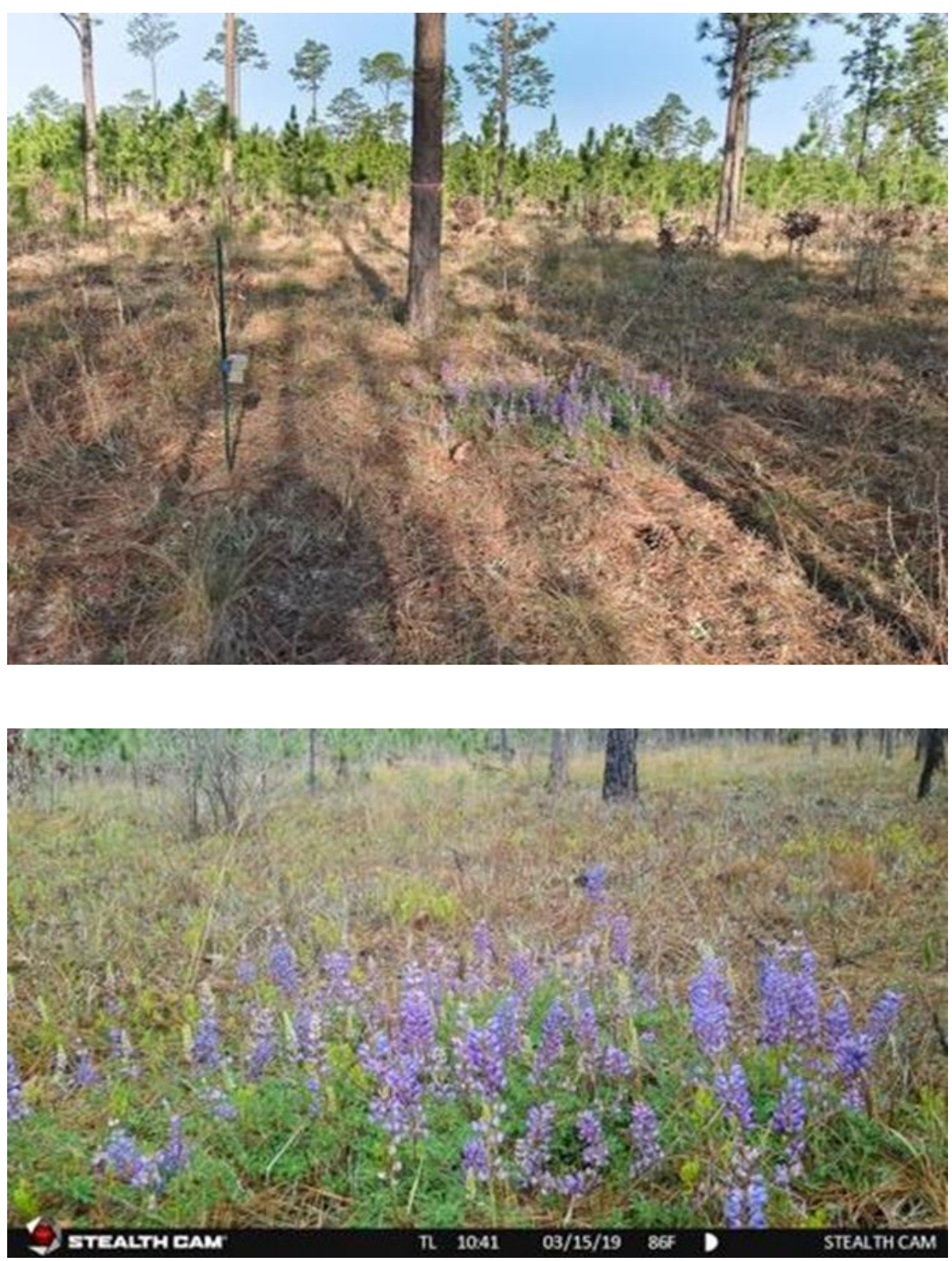

FIGURE I: The placement of the camera trap in relation to the sundial lupine (Lupinus perennis) patch.
FIGURE 2: An example camera trap image taken by the StealthCam trailcam at the sundial lupine (Lupinus perennis) patch. lupine patch and aimed slightly downward (away from the sun) so that photographs covered $>95 \%$ of the patch (Fig. I and 2). Images were taken every 5 seconds from $1000 \mathrm{~h}$ to I700 h on March I4, 2019 (Day I), and from $0800 \mathrm{~h}$ to I400 h on March I5, 2019 (Day 2), when the 32 GB SD card storage was full. Each image contained date, time, and ambient temperature. Ambient conditions were predominantly sunny ( $60 \%$ of the time) with light winds and temperatures of $16^{\circ} \mathrm{C}$ at $0800 \mathrm{~h}$ and $39^{\circ} \mathrm{C}$ at $1700 \mathrm{~h}$.

On Day I, we also conducted a survey of adult $C$. irus on all other known patches of $L$. perennis in the $\operatorname{MHU}(N=$ I05). Four teams of at least two observers each conducted modified Pollard walks to survey all patches in a manner that minimized the chance of duplicate counting while maximizing the chances of detecting all C. irus present (Pollard 1977, Matteson et al. 2012). Surveys were conducted from I000h to $\mathrm{I} 500 \mathrm{~h}$.
We reviewed each image for the presence of flying insects (events). Events included all images where the same individual was seen over sequential photos. Events separated by at least one image with no flying insect presence were treated as new events. When an insect was detected, we zoomed in on the image and categorized individuals as identifiable or not identifiable, and whether they were in flight. Identifiable individual lepidopterans were further categorized to the lowest taxonomic level image quality allowed.

\section{RESULTS AND DISCUSSION}

Of the 9586 photos taken, we had 208 events containing 219 individuals. Despite less than ideal image quality, of these, $2 \mathrm{I} 2(96.80 \%)$ individuals were identifiable at least to Order and only $7(3.20 \%)$ were totally unidentifiable (Fig. 3A-F) All unidentifiable insects were in flight, but most individuals in flight could still be identified. Of individuals in flight, 69 

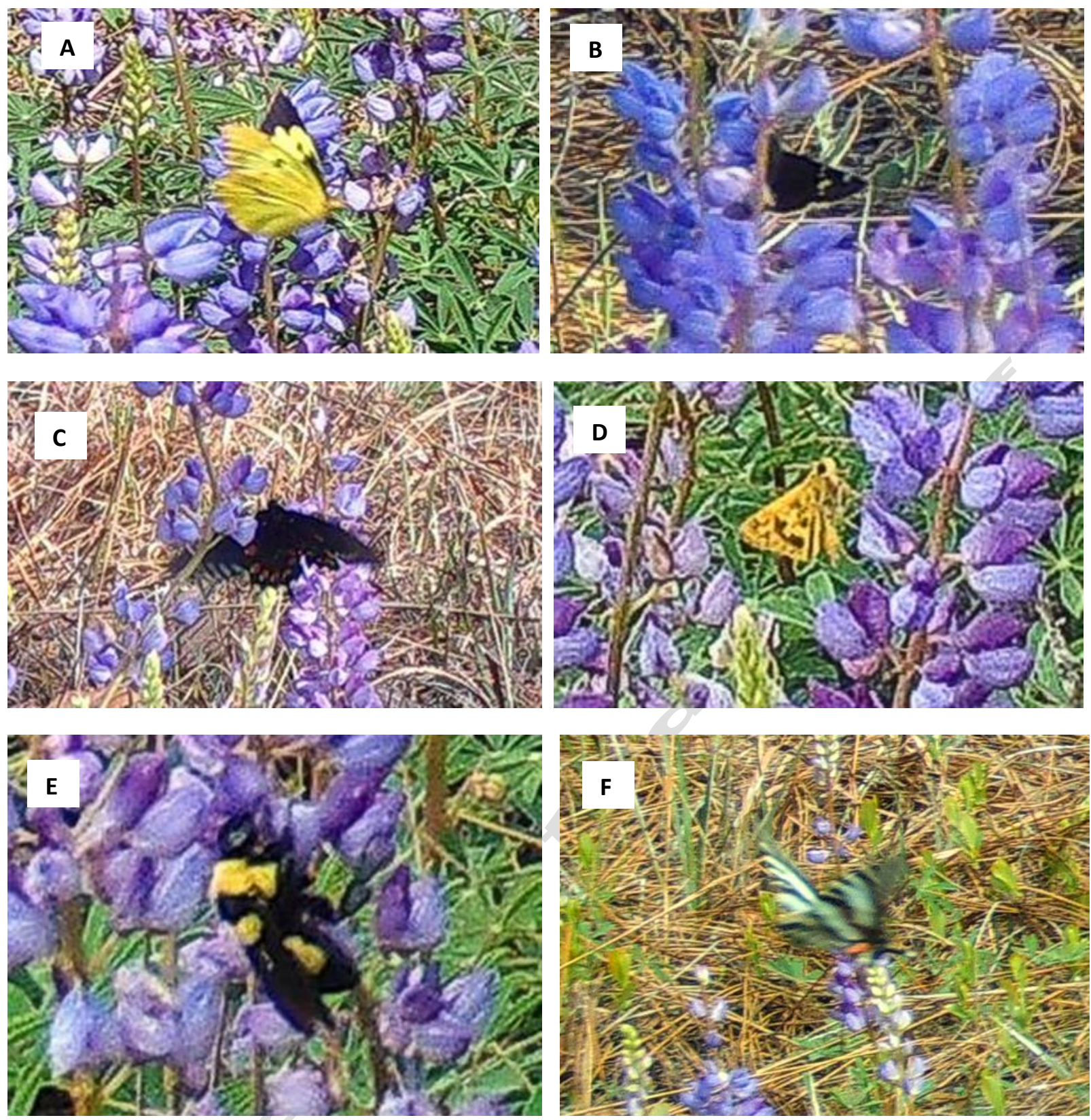

Figure 3: Camera trap images taken at sundial lupine (Lupinus perennis) patch: (A) southern dogface (Colias cesonia); (B) cloudywing (Thorybes sp.); (C) pipevine swallowtail (Battus philenor); (D) whirlabout (Polites vibex); (E) bumblebee (Bombus spp.); (F) zebra swallowtail (Eurytides marcellus)

out of $76(90.79 \%)$ were identified at least to Order. Of those identifiable, I3I (6I.79\%) were Hymenoptera and 8I (38.21\%) were Lepidoptera. No individuals were identified as Diptera. A vast majority of photographed lepidopterans $76 / 81$ (93.83\%) were identifiable to family, and identification reached $100 \%$ if individuals alighted on plants or were photographed in a stationary position. Identified families included Hesperiidae, Papilionidae, Pieridae, and Pyrginae. In some cases (20 events), the individual lepidopteran was identified to species. These species ranged in size from tiger swallowtail (Papilio glaucus), pipevine swallowtail (Battus philenor), and zebra swallowtail (Eurytides marcellus), to southern dogface (Zerene cesonia), and cloudywings (Thorybes spp.), to those as small as the whirlabout (Polites vibex). The adult surveys of other patches yielded 76 adult $C$. irus.

We did not observe any $C$. irus in the photo events. This is not surprising given how few $C$. irus were observed during the adult surveys performed simultaneously by human observers. The lack of $C$. irus encounters could relate to factors other than the use of a camera. The patch was isolated from the nearest known occupied patches by $>I \mathrm{~km}$, and the nearest patch had only a single observation of a $C$. irus adult on March I4. However, we believe the probability of identifying a $C$. irus would have been high if an individual had been present. Lepidopteran individuals were identifiable to family $100 \%$ of the time when they were alight, hovering, or flying relatively slowly. Therefore, the oviposition behavior of 
C. irus lends itself to successful capture with this technique. Also, the wingspan of the $C$. irus is comparable to that of $P$. vibex (Cech \& Tudor 2005), which was successfully detected and identified. Thus, given the right time of year and a larger spatial and temporal extent, it would be possible to monitor this small, rare species using this method.

Despite the successful identification of the insects in this study, trailcams are not without their shortcomings. The model used in this study could only handle a 32GB SD card that filled to capacity after 15 hours of operation. Assuming a I2 hr day-length, this would require $25 \mathrm{~GB}$ of space per day of recording. This space per day requirement could be halved by decreasing the photo frequency to once per IO seconds instead of the once per 5 seconds we used here. This may be acceptable for $C$. irus detection, but not other species that spend less time at an inflorescence. Alternatively, use of multiple SD cards could allow cards to be downloaded and redeployed every other day to provide more continuous monitoring of a site. However, this storage space issue is also contingent on another factor. The StealthCam had a 16 megapixel native resolution for images captured $(5,333 \mathrm{x}$ 3,000 pixels per image). This high amount of definition filled storage space quickly. Conversely, the PlotWatcher Pro took images at a 0.9 megapixel native resolution (I280 x 720 pixels per image) taking up less storage space, but producing images that could not be used for insect identification at a $1 \mathrm{~m}$ distance from the flowers. Therefore, an optimum between resolution and storage space lies between these two cameras used in this study under this study's conditions. If possible, we recommend prioritizing resolution and image quality over storage space.

The method of surveying a patch for pollinators should depend on the level of accuracy desired weighed against the costs of surveying. Ground teams were able to sample all known lupine patches for frosted elfins at a rate of about 5.25 patches/team/hour. Comparatively, the trailcam was able to survey over a much broader length of time (two days) which can give a more accurate sense of presence/absence of the butterfly at that patch. Additionally, stochastic events such as rain, temperature, and wind may have more significant impacts on the surveys if sampling occurs over only one day. While the ability to identify butterflies to family, genus, or species will depend on what is flying at the time and location of the camera trap, we believe this camera is an effective, affordable, and relatively easy-to-use tool for monitoring butterfly visitation in circumstances similar to those used here for this sandhills-ecosystem flower. And, we believe this technique holds promise for future monitoring of $L$. perennis patches for C. irus.

\section{ACKNOWLEDGEMENTS}

The authors are grateful to and thank the following for their invaluable contributions: Jean McElveen for overall support of and assistance with the project; Jim Cox, Tall Timbers Research Station, for loan of the Day 6 PlotWatcher trailcam, review of the manuscript and for his overall support; Wilson Baker, Virginia Craig, David Harder, Dean Jue, Sally Jue and Brian Lloyd for data collection; and John Viehman, Trailcampro.com, for expert advice on various trailcam models and their capabilities.

\section{REFERENCES}

Cech R, Tudor G (2005) Butterflies of the east coast: an observer's guide. Princeton University Press. Princeton, New Jersey.

Edwards J, Smith GP, McEntee MHF (2015) Long-term time-lapse video provides near complete records of floral visitation. Journal of Pollination Ecology I6:9I-I00.

Georgian E, Fang Z, Emshwiller E, Pidgeon A (2015) The pollination ecology of Rhododendron floccigerum franchet (Ericaceae) in Weixi, Yunnan Province, China. Journal of Pollination Ecology I6:72-8I.

Hobbhahn N,Steenhuisen S-L, Olsen T, Midgley JJ, Johnson SD (2017) Pollination and breeding system of the enigmatic South African parasitic plant Mystropetalon thomii (Mystropetalaceae): rodents welcome, but not needed. Plant Biology 19:775-786.

Kobayashi S, Gale SW, Denda T, Izawa M (2019) Civet pollination in Mucuna birdwoodiana (Fabaceae:Papilionoideae). Plant Ecology 220:457-466.

Matteson DC, Taron DJ, Minor ES (2012) Assessing citizen contributions to butterfly monitoring in two large cities. Conservation Biology 26:557-564.

O'Connell AF, Nichols JD, Karanth KU (20II). Camera traps in animal ecology: methods and analyses. Tokyo: Springer.

Phon C, Kirton KG, Yusoff N (2017) Monitoring butterflies using counts of puddling males: A case study of the Rajah Brooke's Birdwing (Trogonoptera brookiana albescens). PLoS ONE I2(I2): e0I89450.

Pollard E (1977) A method for assessing changes in the abundance of butterflies. Biological Conservation I2:I I5-I24.

Steen R, Aase ALTO (20II) Portable digital video surveillance system for monitoring flower-visiting bumblebees. Journal of Pollination Ecology 5(I3) 20II, pp 90-94.

Swengel AB (1996) Observations of Incisalia irus (Lepidoptera: Lycaenidae) in central Wisconsin 1988-95. Great Lakes Entomologist 29:47-62.

Thom MD, Daniels J (2017) Patterns of microhabitat and larval host-plant use by an imperiled butterfly in north Florida. Journal of Insect Conservation 2I:39-52.

van der Kroft T, Roberts DG, Krauss SL (2019) The critical role of honeyeaters in the pollination of the catspaw Anigozanthos humilis (Haemodoraceae). Australian Journal of Botany 67:28I-289. 